\title{
Etika Agen Asuransi Allianz Syariah Dalam Memasarkan Produk Asuransi Jiwa Pada PT. Asuransi Allianz Kota Palu
}

Sitti Musyahidah ${ }^{1 *}$, Nur Asizah², Rahmawati Rahmawati ${ }^{3}$

${ }^{1}$ Ekonomi Syariah, Fakultas Ekonomi dan Bisnis Islam, IAIN Palu

2 Ekonomi Syariah, Fakultas Ekonomi dan Bisnis Islam, IAIN Palu

${ }^{3}$ Ekonomi Syariah, Fakultas Ekonomi dan Bisnis Islam, IAIN Palu

ABSTRAK

Tujuan dari penelitian ini untuk mengetahui bagaimana etika agen asuransi Allianz syariah dalam memasarkan produk asuransi jiwa pada PT. Asuransi Allianz Kota Palu, kemudian untuk mengetahui bagaimana prespektif ekonomi Islam tentang etika agen asuransi Allianz syariah dalam memasarakan produk asuransi jiwa pada PT. Asuransi Allianz syariah Kota Palu. Jenis penelitian yang digunakan adalah deskriptif dengan menggunakan pendekatan kualitatif. Berdasarkan hasil penelitian dan analisis yang telah dilakukan maka dapat diketahui bahwa etika agen asuransi Allianz Syariah kota Palu dalam memasarakan produk tidak ada pelatihan khusus dari perusahaan tentang asuransi syariah, namun para agen diberi beberapa persyaratan dan diperkuat dengan kode etik agen dari Allianz berupa buku panduan. Strategi pemasaran produk asuransi jiwa pada PT. Asuransi Allianz Kota Palu menurut ekonomi Islam belum berjalan dengan baik sesuai dengan prinsip-prinsip Ekonomi Islam karena ada beberapa pelanggaran-pelanggaran yang dilakukan mulai dari perekrutan keagenan sampai dengan sistemnya yang kurang diperhatikan oleh perusahaan.
INFORMASI

ARTIKEL

Katakunci:

Asuransi, pemasaran, produk asuransi, Allianz 


\section{Pendahuluan}

Kehidupan manusia di dunia ini pada dasarnya mengandung berbagai hal yang menunjukan sifat hakiki dari kehidupan, setiap manusia akan mengalami yang namanya musibah, dan musibah yang menimpa manusia adalah kehendak Allah swt yang tidak bisa dicegah maupun dihindari. Masalah yang selalu dihadapi manusia kemungkinan adalah sakit, kecelakanan, usia senja, serta kematian, kematian ini merupakan hal yang pasti namun kapan terjadinya tidak ada yang bisa pastikan. Upaya untuk mengatasi sifat alamiah yang berwujud sebagai suatu keadaan yang tidak pasti, antara lain dengan berupaya melimpahkannya kepada pihak-pihak lain di luar dirinya sendiri atau badan usaha lain. Adapun lembaga tersebut yang menjamin sekiranya timbul suatu peristiwa yang tidak diinginkan tersebut dikenal dengan Asuransi. ${ }^{1}$

Asuransi memang tidak bisa mencegah musibah yang akan terjadi namun setidaknya dapat mengurangi beban akibat krisis keuangan yang terjadi pada diri seseorang atau kelompok masyarakat. Asuransi sebagai lembaga keuangan yang bergerak dalam bidang pertanggungan merupakan sebuah institusi modern hasil temuan dari dunia Barat yang lahir bersamaan dengan adanya semangat pencerahan (Renaissaince). Institusi ini bersama dengan lembaga keuangan bank menjadi motor penggerak ekonomi pada

1 Sri Rejeki Hartono, Hukum Asuransi Syariah dan Perusahaan Asuransi, Cet, ke I (Jakarta: Sinar Grafika, 2008), 2. era modern dan berlanjut hingga sekarang. Dasar yang menjadi semangat kerja operasional asuransi modern adalah berorientasi pada sistem kapitalis yang intinya hanya bermain dalam perkumpulan modal untuk keperluan pribadi atau golongan tertentu, dan kurang atau tidak mempunyai akar untuk pengembangan ekonomi pada tataran yang lebih komprehensif. ${ }^{2}$

Berbeda halnya dengan asuransi syariah. asuransi dalam literatur keislaman lebih banyak bernuansa sosial dari pada bernuansa ekonomi atau profit oriented (keuntungan bisnis). Hal ini dikarenakan oleh aspek tolongmenolong yang dikenal dengan istilah ta'awun, yaitu prinsip hidup melindungi dan saling menolong atas dasar ukhuwah islamiyah antara sesama anggota peserta asuransi syariah dalam menghadapi resiko yang kemungkinan akan terjadi. aspek ini menjadi dasar utama dalam menjalankan praktek asuransi dalam Islam. ${ }^{3}$

Berdasarkan latar belakang tersebut penulis tertarik meneliti tentang Etika Agen Asuransi Allianz Syariah dalam Memasarkan Produk Asuransi Jiwa Pada PT. Asuransi Allianz Kota Palu ditinjau dalam Prespektif Ekonomi Islam.

\section{Tinjauan Pustaka}

\subsection{Pengertian Etika}

Etika secara etimologi berasal dari bahasa Yunani kuno yaitu ethos yang memiliki arti kebiasaan, adat,

2 Husain Syabatah, Asuransi dalam Prespektif Syariah, Cet, II (Jakarta: Sinar Grafika Offset, 2006), 23.

3 Hasan Ali, Asuransi Dalam Prespektif Hukum Islam , (Jakarta: Kencana, 2004), 55.

e-ISSN: 2686-6633 
akhlak, watak, perasaan, sikap, cara berfikir. Dalam pengertian ini etika berkaitan dengan kebiasaan hidup yang baik, baik pada diri seseorang maupun pada kelompok masyarakat yang diwariskan pada satu orang ke orang lain kemudian terus berulang sebagai sebuah kebiasaan. ${ }^{4}$

Etika pada umumnya diidentikan dengan moral atau moralitas tetapi, meskipun sama terkait dengan tindakan baik buruk manusia, etika dan moral memiliki pengertian yang berbeda, moral lebih terkait dengan nilai baik dan buruk setiap perbuatan manusia, sedangkan etika lebih merupakan ilmu yang mempelajari tentang baik dan buruk tersebut. ${ }^{5}$ Etika Islam berdasarkan Al-qur'an dan Hadis, ajaran etika Islam menentukan bentuk yang sempurna dengan titik pangkalnya pada Allah dan akal manusia. Intinya mengajak manusia agar percaya kepada Allah. Dialah pencipta, pemilik, pemelihara, pelindung, pemberi rahmat, pengasih dan penyayang kepada mahluk-mahluknya. ${ }^{6}$

Dengan demikian berbisnis dalam ajaran Islam sangat dijunjung tinggi guna untuk menyelamatkan manusia dari sifat rakus, tamak, curang, dan tidak perduli terhadap saudara selingkungannya. Titik sentral ekonomi Islam adalah menetukan kebebasan manusia untuk bertindak dan bertanggung jawab karena

4 Abdul Aziz, Etika Bisnis Prespektif Islam Implementasi Etika Islam Untuk Dunia Usaha, Cet ke I (Bandung, Alfabeta cv 2013), 48

5 Ibid, 50.

6 M. Yatimin Abdullah, Pengantar Studi Etika, (Jakarta: Raja Grafindo Persada 2006), 525. kepercayaannya terhadap Allah swt. Seperti firman Allah dalam QS. AlBaqarah, 2 : 188).

a. Etika Ekonomi Islam

Ekonomi Islam adalah suatu sistem ekonomi yang tujuan utamanya adalah mewujudkan keadilan dan kesejahteraan secara merata adapaun yang dimaksud dengan kesejahtraan (Al-falah) adalah sebuah kondisi dimana al-daruruyyat al-khams (lima kebutuhan primer) dapat terpelihara dan terjamin keberadaannya dalam kehidupan manusia itu sendiri. Lima kebutuhan primer tersebut adalah terdiri dari pemeliharaan agama, jiwa, akal keturunan dan harta.

Maka untuk meralisasikan tujuan ini perlu dibutuhkan suatu sistem yang akan mendukung terciptanya tujuan tersebut yaitu berupa nilai dan prinsipprinsip syariah. Sistem nilai pada hakikatnya sesuatu yang akan memberikan makna dalam kehidupan manusia dalam setiap peran yang dilakukan.

Dalam sistem ekonomi Islam terdapat sistem yang saling terkait antara satu dengan yang lainnya, yaitu mencakup pandangan dunia dan moral yang mempengaruhi, membimbing dam membantu manusia merealisasikan sasaran-sasaran kemanusiaan yang berkebutuhan guna mewujudkan keadilan dan kesejahteraan. Maka untuk merealisasikan tujuan ini terdapat lima prinsip dalam Etika Ekonomi Islam yaitu: tauhid, keadilan, khalifah, kebebasan dan tanggung jawab. ${ }^{7}$

7 Ahmad Mujahidin Ekonomi Islam (Ed, Revisi, cet. 2 Jakarta: Rajawali Pers. 2013), 24.

e-ISSN: 2686-6633 


\subsection{Pengertian Agen Asuransi}

Pada umumnya, pemasaran asuransi diselenggarakan melalui repsentatives perusahaan asuransi yang dikenal sebagai agen. Agen Asuransi adalah siapa saja yang dikuasakan oleh perusahaan asuransi untuk mencari, membuat, mengubah, atau mengakhiri kontrak-kontrak asuransi antara perusahaan asuransi dengan publik. Yang terlibat pula dalam proses pemasaran asuransi adalah makelar asuransi. Makelar asuransi adalah seseorang yang untuk suatu pertimbangan mencari dan menegosiasikan kontrak asuransi untu seorang yang ditanggung bukan dari perusahaan asuransi. $^{8}$

Agen pemasar adalah ujung tombak yang berfungsi sebagai penjaga citra perusahaan serta indutri asuransi di mata masyarakat. Agen pemasar syariah tidak boleh keliru mempromosikan produk, menginformasikan produk, hingga menjual produk. Karena itu, profesi agen pemasar asuransi syariah sekaligus keberimbangan pengetahuannya antara pengetahuan syariah dan pengetahuan ekonomi di kedepankan untuk menjawab kebutuhan pasar asuransi syariah di Indonesia. Seorang agen dalam sebuah usaha asuransi ditunjuk dan diberi wewenang oleh perusahaan asuransi untuk bertindak atas nama perusahaan

\section{Metode Penelitian}

Metode merupakan suatu prosedur tata cara megetahui sesuatu yang

8 Hasyimi Ali, Pengantar Asuransi cet ke II, (Jakarta: Bumi Aksara, 1995), 94. mempunyai langka sistematis. ${ }^{9}, 10$ Dalam penulisan karya ilmiah, penulis menggunakan metode pendekatan kualitatif dan jenis penelitian deskriptif. Metode kualitatif dapat digunakan untuk mengungkap dan memahami sesuatu di balik fenomena yang sedikit pun belum diketahui. Metode ini dapat juga digunakan untuk menambah wawasan tentang sesuatu yang belum diketahui. $^{11}$ Peneliti dalam penelitian kualitatif ini akan mencoba mengerti makna suatu kejadian atau peristiwa dengan mencoba berinteraksi dengan orang-orang dalam situasi/fenomena tersebut.

Penggunakan metode kualitatif dalam penelitian ini dengan beberapa pertimbangan. Pertama, menyesuaikan metode kualitatif lebih mudah apabila berhadapan dengan kenyataan ganda. Kedua, dapat menyajikan secara langsung hakikat hubungan antara peneliti dengan informan ${ }^{12}$. Ketiga, Metode ini lebih peka dan lebih menyesuaikan diri dengan banyak penajaman pengarah bersama dan

9 Muhammad, Metodologi Penelitian Ekonomi Islam Pendekatan kualitatif, (Jakarta: Rajawali PT. Raja grafindo Persada, 2008), 12.

10 Nurdin, N. (2019). Knowledge Integration Strategy in Islamic Banks. In A. Helena \& S. Bernardete (Eds.), The Role of Knowledge Transfer in Open Innovation (pp. 118138). IGI Global. https://doi.org/10.4018/978-15225-5849-1.ch006

11 Ansel Struss dan Julet Corbin, DasarDasar Penelitian Kualitatif, (Yogyakarta : Pustaka pelajar, 2007), 5.

12 Nurdin, N., Pettalongi, S. S., \& Yusuf, K. (2018). Knowledge Management Model in Syariah Banking. 2018 5th International Conference on Information Technology, Computer, and Electrical Engineering (ICITACEE), 
terhadap pola-pola nilai yang dihadapi. ${ }^{13}$

Lokasi yang menjadi tempat penelitian ini adalah pada PT asuransi Allianz Kota Palu yang beralamat di jalan Moh. Yamin No 75 depan lapangan Walikota V Batulemo, kecamatan Palu Selatan, Propinsi Sulawesi Tengah dan sekarang telah berpindah tempat di jalan Banteng 1 Perumahan Tiara Residence Palu, Birobuli Selatan, Kecamatan Palu Selatan, Kota Palu, Sulawesi Tengah.

Data dikumpul dengan menggunakan teknik observasi, wawancara mendalam dan kajian dari berbabagi dokumen tertulis ${ }^{14}$. Sedangkan analisa data dilakukan dengan menggunakan teknik reduksi dan verifikasi dengan berbagai sumber data $^{15}$. Data yang sudah direduksi kemudian dianalisis dengan mengaku pada konsep teori yang digunakan dalam penelitian ini.

\section{Hasil dan Pembahasan}

13 Nurdin, N., Stockdale, R., \& Scheepers, H. (2014). The Role of Social Actors in the Sustainability of E-Government Implementation and Use: Experience from Indonesian Regencies. System Sciences (HICSS), 2014 47th Hawaii International Conference on System Science,

14 Nurdin, N. (2017). To Research Online or Not to Research Online: Using Internet-Based Research in Islamic Studies Context. Indonesian Journal of Islam and Muslim Societies, 7(1), 31-54.

15 Nurdin, N., \& Yusuf, K. (2020). Knowledge management lifecycle in Islamic bank: the case of syariah banks in Indonesia. International Journal of Knowledge Management Studies, 11(1), $59-80$. https://doi.org/10.1504/ijkms.2020.105073

\subsection{Sejarah singkat PT. Asuransi Allianz} Kota Palu

Allianz merupakan penyedia asuransi dan manjemen asset terbesar di Dunia. Bersama nasabah dan mitra penjualan, Allianz merupakan komunitas keuangan terkuat dengan oprasi terbesar di 70 negara. Lebih dari 70 juta nasabah dan korporasi mengandalkan pengetahuan, jangakauan modal, serta soliditas Allianz. Untuk membantu mereka memanfaatkan peluang keuangan sebaik mungkin, dan untuk menghindari dan menjaga diri terhadap resiko.

Selama 125 tahun Allianz hadir di dunia, strategi bisnis jangka panjang kami mampu melalui berbagai krisis politik, ekonomi dan keuangan. Dengan menempatkan diri sebagai mitra terpercaya, fokus yang kuat pada nasabah, meningkatkan pelayanan dan kehadiran secara global, serta memberikan pengalaman yang konsisten merupakan faktor-faktor pendukung kesuksesan kami.

Asia pasifik adalah salah satu dari tiga regional yang tumbuh pesat di Allianz. Dengan kekayaan dan kebudayaan, bahasa dan adat istiadat yang beraneka ragam. Adalah karakteristik dari regional ini. Allianz hadir di Asia pasifik pada tahun 1917, di pesisir cina dengan menyediakan asuransi kebakaran dan asuransi jiwa pengangkutan. Di Asia Pasifik Allianz hadir dalam 15 pasar dengan fokus bisnisnya pada asuransi umum, jiwa, kesehatan dan manajemen asset dengan lebih dari 14.500 staf Allianz melayani kebutuhan lebih dari 21,5 juta nasabah di kawasan ini kemampuan Allianz 
untuk beradabtasi dengan cepat terhadap kebutuhan lokal menjadi kunci sukses. ${ }^{16}$

Allianz hadir di Indonesia sejak 1981 melalui kantor perwakilan di Jakarta. Tahun 1989, PT. Asuransi Allianz Utama Indonesia resmi beroprasi memberikan pelayanan di bidang asuransi umum. Di tahun 1996, Allianz melengkapi pelayanan asuransinya di Indonesia dengan mendirikan PT. Asuransi Allianz Life Indonesia yang bergerak di bidang asuransi jiwa, kesehatan dan pensiun. Pada tahun 2006, kedua perusahaan memulai bisnis asuransi syariah.

Di tahun 2007, Allianz Indonesia memperkenalkan Allianz Center sebagai sebuah konsep one stop solutions, dimana nasabah dan agen asuransi Allianz bisa mendapatkan pelayanan asuransi di satu tempat. Allianz center telah beroprasi di Jakarta, Surabaya, Bandung dan Denpasar. kini bersamasama, Allianz Indonesia hadir di 40 kota dengan 80 titik pelayanan, didukung oleh 14.000 agen, dan sekitar 1000 karyawan dan mitra perbankan yang solid untuk melayani nasabah Allianz. ${ }^{17}$

Pada tahun 2010 Allianz Indonesia yang terdiri dari Allianz utama dan Allianz Life Indonesia mencetak total premi bruto sebesar Rp. 5,6 triliun. Saat ini, Allianz menjadi salah satu pemimpin pasar yang dipercaya melayani lebih dari 1,8 jiwa baik dari individu maupun grup.

16 Allianz Profil, diakses melalui https://www.allianz.co.id/tentangkami/profil/visi-misi pada tanggal 06 Oktober 2019.

17 Ibid.
Sejak April 2011, kantor pusat Allianz di Jakarta telah menempati gedung baru Allianz Tower di kawasan kuningan persada Jakarta Selatan. Allianz tower dibangun dengan memperhatikan prinsip-prinsip ramah lingkungan sebagai bentuk nyata dari komitmen Allianz terhadap kelestarian lingkungan. PT. Asuransi Alianz Indonesia berdiri pada 21 Desember 1989. Allianz Utama hadir di Indonesia memberikan solusi asuransi umum yaitu asuransi kendaraan bermotor, properti, rekayasa pengangkutan dan asuransi aneka baik konvensional maupun syariah untuk melayani kebutuhan asuransi nasabah perorangan, bisnis kecil menengah dan untuk koprasi atau industri.

Allianz Life Indonesia berdiri pada tanggal 16 Agustus tahun 1996 untuk memberikan solusi asuransi jiwa dan kesehatan konvensional dan syariah bagi nasabah individu, juga program kesejahteraan karyawan dan dana pensiun bagi nasabah koperasi.

Dalam memberikan pelayanan yang prima, Allianz Life didukung oleh lebih dari 14.000 tenaga penjual melalui Allianz Star Network yang tersebar di 80 kantor pemasaran yang berlokasi di 43 kota di seluruh Indonesia mulai dari Banda Aceh sampai dengan Jaya Pura, selain itu, didukung oleh account executive yang handal serta menjalin kerja sama dengan konsultan asuransi, terdepan di Indonesia dan telemarketing. 18

Seiring dengan berkembangnya bisnis syariah yang semakin maju PT. Asuransi Allianz Indonesia

18 Ibid. 
berkomitmen terus untuk memberikan layanan terbaik bagi seluruh lapisan masyarakat sehingga mampu berperan dalam meningkatkan pembangunan ekonomi syariah, demi masa depan Indonesia yang gemilang. Dalam rangka memperluas jaringan asuransi Allianz terutama yang berbasis syariah kepada masyarakat diperluakan usaha dengan sungguh-sungguh, jujur, amanah, dan dapat dipercaya disertai dengan perencanaan salah satunya adalah dengan membuka kantor cabang yang belum terjangkau oleh kantor pusat.

Pada tanggal 17 Agustus 2016 perusahaan asuransi Allianz membuka cabang tersebut ialah PT. Asuransi Allianz cabang Palu. Bertempat di ruko D'Vatulemo nomor 7. Jalan Profesor Muhammad Yamin, Lolu Utara, Palu Selatan. Kota Palu Sulawesi Tengah. Namun pada tanggal 12 Agustus 2019 kantor cabang ini pindah lokasi di Jalan Banteng 1 Perumahan Tiara Residence Palu No 10. Birobuli Selatan, Kecamatan Palu Selatan Yang dipimpin oleh bapak Ivan Satriadi Artawijaya dan ada beberapa agen asuransi Allianz kemudian satu orang sebagai administrasi, sekarang kantor tersebut merupakan kantor agency yang dipergunakan oleh agen-agen untuk melakukan prospek jika ada calon nasabah atau calon agen yang ingin bergabung.

\subsection{Produk PT. Asuransi Allianz Syariah Kota Palu}

Adapun produk Asuransi Syariah pada Allianz adalah: ${ }^{19}$

\footnotetext{
${ }^{19}$.Allianz, Allisya Protection Plus, diakses Melalui http://www.allianz.co.id/produk/asuransisyariah/allisya-protection-plus
}

1) Allisyah Protection Plus

Allisyah Protection Plus adalah sebuah program asuransi jiwa yang dipadukan dengan investasi berbasis syariah

2) AlliSyah Rupiah Fixed Income Fund

Tujuan investasi dari dana ini adalah untuk menyediakan pendapatan yang relatif stabil dengan menjaga modal dengan jangka panjang

3) AlliSyah Rupiah Balanced Fund

Tujuan investasi dari dana ini adalah untuk mencapai pertumbuhan modal jangka panjang dengan menghasilkan pendapatan yang relatif stabil

\subsection{Etika agen asuransi dalam memasarkan produk asuransi jiwa}

Asuransi merupakan sebuah produk keuangan yang memberikan penangguhan resiko bagi nasabahnya. sebagai seorang pemasar pastinya memberikan informasi sejelas-jelasnya terkait dengan produk asuransi yang mungkin akan berguna bagi nasabahnya melihat dari kegunaan untuk masa depan nasabahnya. namun masih banyak masyarakat yang percaya bahwa asuransi adalah produk yang terlalu ribet ditambah dengan banyaknya penipuan yang terjadi sehingga menumbulkan rasa tidak percaya tehadap produk sekaligus pemasar atau agennya. Maka perlu adanya standar etika tinggi agar dalam melakukan pemasaran terhadap produk tersebut bisa dilaksanakan dengan baik.

AAJI atau Asosiasi Asuransi Jiwa Indonesia, merupakan wadah organisasi bagi para agen dimana menerapkan standar bagaimana menjadi agen yang

pada tanggal 06 Oktober 2019.

e-ISSN: $2686-6633$ 
benar. Dengan dibekali materi dan ujian lisensi diperuntukan bagi calon agen yang memang sesuai dengan syarat yang baik sesuai dengan standar yang diterapkan oleh AAJI. Adapun sistem prekrutan agen baru yang ingin bergabung dalam asuransi Allianz Kota Palu harus melengkapi berkas-berkas yang telah ditentukan oleh perusahaan yaitu sebagai berikut:20

a. Foto copy KPT yang masih berlaku dua lembar

b. Pas foto berwarna terbaru $3 \times 4 \quad(4$ lembar)

c. Foto copy NPWP kalau ada

d. Foto copy buku tabungan yang masih aktif (untuk transfer komisi penjualan)

e. Biaya mengikuti ujian lisensi AAJI konvensional dan syariah sebesar $\mathrm{Rp}$ 285.000, kalau konvensional saja Rp. 225.000 .

Apa bila seorang calon agen sudah memenuhi persyaratan dan telah mengikuti ujian lisensi yang diadakan oleh AAJI dan dinyatakan lulus serta mendapatkan sertifikat dan nomor lisensi agen asuransi. Maka agen tersebut telah siap menjadi seorang agen asuransi Allianz profesional.

\section{Kesimpulan}

Dari hasil penelitian tentang Etika Agen Asuransi Allianz Syariah dalam Memasarkan Produk Asuransi Jiwa Pada PT. Asuransi Allianz Kota Palu maka dapat disimpulkan bahwa etika agen asuransi Allianz Syariah Pada PT. Asuransi Allianz Kota Palu yang dilakukan tidak ditentukan oleh perusahaan, namum para agen diberi beberapa persyaratan dan diperkuat dengan kode etik agen dari Allianz berupa buku panduan. Dalam hal ini juga tidak ada pelatihan-pelatihan khusus untuk agen-agen syariah yang membahas tentang etika ekonomi Islam atau ekonomi syariah. ada beberapa agen Allianz yang melakukan strategi pemasaran sebagai berikut: Attention atau perhatian, Interested atau tertarik, design atau desain, Action atau lakukan.

Strategi pemasaran Produk Asuransi Jiwa pada PT. Asuransi Allianz Kota Palu menurut Ekonomi Islam belum berjalan dengan baik sesusai dengan Prinsip Ekonomi Islam karena ada beberapa pelanggaran-pelanggaran yang dilakukan mulai dari perekrutan keagenan sampai dengan sistem yang kurang diperhatikan oleh perusahaan.

\section{Daftar Pustaka}

Ahmad Mujahidin Ekonomi Islam (Ed, Revisi, cet. 2 Jakarta: Rajawali Pers. 2013), 24.

Aziz Abdul, Etika Bisnis Prespektif Islam Implementasi Etika Islam Untuk Dunia Usaha, Bandung, Alfabeta cv Allianz Profil, diakses melalui https://www.allianz.co.id/tenta ng-kami/profil/visi-misi pada tanggal 06 Oktober 2019.

Allianz, Allisya Protection Plus, diakses Melalui

http://www.allianz.co.id/produ $\mathrm{k} /$ asuransi-syariah/allisyaprotection-plus pada tanggal 06 Oktober 2019
${ }^{20}$ Aisyah "Wawancara" di PT. Allianz Syariah Cabang Palu pada tanggal 07 Oktober 2019. 
Abdullah M. Yatimin, Pengantar Studi Etika, Jakarta: Raja Grafindo Persada

Ali Hasyimi, Pengantar Asuransi cet ke 2, Jakarta: Bumi Aksara

Hartono Sri Rejeki, Hukum Asuransi Syariah dan Perusahaan Asuransi, Jakarta: Sinar Grafika

Hasan Ali, Asuransi Dalam Prespektif Hukum Islam , (Jakarta: Kencana, 2004), 55

Hasyimi Ali, Pengantar Asuransi cet ke II, (Jakarta: Bumi Aksara, 1995), 94.

Husain Syabatah, Asuransi dalam Prespektif Syariah, Cet, II (Jakarta: Sinar Grafika Offset, 2006), 23.

M. Yatimin Abdullah, Pengantar Studi Etika, (Jakarta: Raja Grafindo Persada 2006), 525.

Nurdin, N., Stockdale, R., \& Scheepers, H. (2014). The Role of Social Actors in the Sustainability of EGovernment Implementation and Use: Experience from Indonesian Regencies. System Sciences (HICSS), 2014 47th Hawaii International Conference on System Science,

Nurdin, N. (2017). To Research Online or Not to Research Online: Using Internet-Based Research in Islamic Studies Context. Indonesian Journal of Islam and Muslim Societies, 7(1), 31-54.

Nurdin, N., Pettalongi, S. S., \& Yusuf, K. (2018, 27-28 Sept. 2018). Knowledge Management Model in Syariah Banking. 2018 5th International Conference on Information Technology,
Computer, and Electrical Engineering (ICITACEE)

Nurdin, N. (2019). Knowledge Integration Strategy in Islamic Banks. In A. Helena \& S. Bernardete (Eds.), The Role of Knowledge Transfer in Open Innovation (pp. 118-138). IGI Global.

https:/ / doi.org/10.4018/978-15225-5849-1.ch006

Nurdin, N., \& Yusuf, K. (2020). Knowledge management lifecycle in Islamic bank: the case of syariah banks in Indonesia. International Journal of Knowledge Management Studies, 11(1), 59-80. https:/ / doi.org/10.1504/ijkms.20 20.105073

Sri Rejeki Hartono, Hukum Asuransi Syariah dan Perusahaan Asuransi, Cet, ke I (Jakarta: Sinar Grafika, 2008), 2

Syabatah Husain, Asuransi dalam Prespektif Syariah, Jakarta: Sinar Grafika Offset.

Supardi, Metodologi penelitian kualitatif, Bandung: PT Remaja Rosdakarya 